Este libro forma parte del acervo de la Biblioteca Jurídica Virtual del Instituto de Investigaciones Jurídicas de la UNAM

\title{
LA SALUD SEXUAL Y REPRODUCTIVA DE LAS MUJERES ANTE LA PANDEMIA DEL GOVID-19
}

\author{
Raffaela ScHIAVON
}

\author{
SUMARIO: I. Introducción. II. Las múltiples vulnerabilidades de las muje- \\ res ante la pandemia. III. Conclusiones. Como proteger los derechos y la salud \\ sexual y reproductiva en tiempos de pandemia.
}

\section{INTRODUCGIÓN}

Esta pandemia ha llegado a este mundo, inicialmente de manera callada y desde lejos, después de manera cercana y explosiva. Independientemente de que hayamos sido los primeros o los últimos en caer, que nos haya sumergido en un brote epidémico brusco y acelerado, o bajo una curva más plana y lenta, nos ha encontrado, a la mayoría de los países, impreparados, incrédulos, algunos escépticos, otros apanicados, y varios más preocupados y ocupados en combatirla.

A más de medio año de haber azotado a todos los países del mundo, y haber dado claras advertencias de que no tendrá solo una recurrencia estacional, sino de que sigue y seguirá entre nosotros, no tenemos todavía perspectivas sólidas sobre tratamientos curativos ni vacunas. Y esto, a pesar de un esfuerzo nunca antes visto de inversiones e investigaciones, de compromiso altruista y generosísimo de voluntarios, de trabajo incansable y profesional del personal de salud, de clínicos e investigadores, de apuestas billonarias de la industria farmacéutica, y de apuestas personales y políticas de líderes de organismos internacionales y de jefes de países grandes, medianos y pequeños.

Lo que queda claro es que este virus ha sido el traje del emperador de nuestra historia: ha descobijado y expuesto nuestras desnudeces.

Nuestras economías basadas en la explotación de los recursos naturales y humanos, en la concentración de las riquezas, en la profundización de las 
Este libro forma parte del acervo de la Biblioteca Jurídica Virtual del Instituto de Investigaciones Jurídicas de la UNAM

inequidades. Nuestros sistemas de protección social y de salud cada vez más frágiles, y cada vez más olvidadizos de la importancia de las intervenciones básicas de higiene comunitaria e individual (agua potable, jabón, limpieza), de una alimentación saludable, del cuidado de la salud colectiva, de la prevención de las enfermedades crónicas, de mantenerse sanos. Este virus ha expuesto despiadadamente las vulnerabilidades de todo y cada uno de nuestros países, identificándolas rápidamente en cada país y cada sociedad: en los países ricos, ha exterminado a los viejos y a las personas con sobrepeso y obesidad y a los que padecen enfermedades crónicas; en Estados Unidos a los afroamericanos y a los indígenas de la Amazonas en Brasil; a las personas migrantes y a los trabajadores precarios e informales en todos los países del mundo.

En este panorama, no podemos dejar de enfocar nuestra atención en las mujeres. Seguramente algunos se encogerán de hombros ante la terquedad del lente de género con el que persistimos obstinadamente en explorar el mundo y la realidad que nos rodea. Porque es también cierto que las mujeres parecen sistemáticamente estar más protegidas, si no del contagio (la distribución de casos por sexo parece generalmente pareja), sí de las consecuencias mortales del mismo: la distribución de defunciones por sexo se carga pesantemente en los hombres. Hay ciertas posibles explicaciones biológicas que todavía se están investigando: las concentraciones de la enzima ECA2 - cuya porción extracelular el virus usa, como una llave, para entrar a las células, de esta manera "bloqueando" su acción enzimática- parecen ser dependientes de las hormonas y son más elevadas en las mujeres que en los hombres, dejando por tanto más enzima libre y activo; el sistema inmunitario en las mujeres parece ser más "apto" para organizar las defensas ante el ataque viral, entre otros mecanismos posibles.

\section{LAS MÚLTIPLES VULNERABILIDADES DE LAS MUJERES ANTE LA PANDEMIA}

Sin embargo, a pesar de estas aparentes ventajas del sexo femenino, nuestra insistencia en señalar a las mujeres está sólidamente anclada en hechos. El nuevo Coronavirus SARS-CoV-2, responsable de la pandemia de COVID-19, visibiliza y agrava no sólo su flanco débil biológico, es decir su rol reproductivo, sino sobre todo sus otras múltiples vulnerabilidades, generadas por el rol reproductivo social, que la cultura y las normas les asignan en la comunidad. 
Este libro forma parte del acervo de la Biblioteca Jurídica Virtual del Instituto de Investigaciones Jurídicas de la UNAM

\section{La vulnerabilidad de las mujeres como usuarias de los servicios de salud sexual y reproductiva}

Como consecuencias del abrumador incremento en la demanda de servicios de salud por COVID-19, la respuesta global del sector ha sido reconvertir clínicas y hospitales hacia la atención de las personas con graves síntomas de insuficiencia respiratoria, divirtiéndola de la atención considerada no esencial ni urgente.

Pero, ¿cómo impacta esto en la salud sexual y reproductiva de mujeres y adolescentes? ${ }^{1}$

Las mujeres, y las personas en general, siguen teniendo relaciones sexuales aun en las situaciones más extremas, durante guerras, desastres naturales, emergencias humanitarias y sanitarias; en estas circunstancias, aumenta además la probabilidad de que las relaciones se den bajo coerción, abuso y violencia. Esto implica que las mujeres siguen teniendo necesidad, esencial y urgente, de una amplia gama de anticonceptivos, incluyendo anticonceptivos de emergencia; de antibióticos y de fármacos antirretrovirales postexposición; de terapias de mantenimiento para personas que viven con VIH y que no pueden interrumpirlas; y de servicios de prevención y atención de la violencia sexual, familiar y de género.

Por otro lado, las mujeres que cursan embarazos deseados, siguen necesitando atención durante el embarazo, el parto y el puerperio, aquí y ahora, urgente y no diferible en el tiempo. Y aquellas que están embarazadas en contra de su deseo o su voluntad, o cuyo embarazo pone en riesgo su salud o su vida, o donde esté comprometida la salud o la integridad del producto, tienen la necesidad urgente de acceder a servicios de aborto seguro, de acuerdo con la interpretación más amplia de la ley.

El impacto de la pandemia en la salud materna - las mujeres embarazadas están desproporcionadamente afectadas por enfermedades respiratorias como la influenza u otras epidemias virales recientes - con el consecuente aumento en la morbimortalidad materna, así como los riesgos sobre sus productos, que van desde una potencial teratogenicidad, la premadurez hasta el bajo peso - serán tratados en otro capítulo de este mismo volumen - Nosotros nos enfocamos específicamente en los impactos en la salud sexual y reproductiva.

1 Declaración del International Medical Advisory Panel (IMAP) sobre el GOVID-19 y los derechos de salud sexual y reproductiva, abril de 2020. disponible en: https://wwre. ippf.org/sites/default/files/2020-04/IMAP\%20Statement\%20on\%20COVID-19\%20impact\%20 on\%20SRHR\%20-\%20Spanish.pdf. 
Este libro forma parte del acervo de la Biblioteca Jurídica Virtual del Instituto de Investigaciones Jurídicas de la UNAM

\section{A. Impacto de la pandemia en la salud sexual y reproductiva}

La Organización Mundial de la Salud reitera que el acceso a servicios y a métodos anticonceptivos (MAG) es siempre, y más aún durante esta pandemia, una de las intervenciones más costo-efectivas para prevenir los embarazos no intencionados, reducir los abortos inseguros y la mortalidad materna globalmente. Es obligación de los gobiernos y de los sistemas de salud garantizar para todas las mujeres el acceso a información, servicios y a todos los métodos anticonceptivos, incluyendo la anticoncepción de emergencia. El Fondo de Población de las Naciones Unidas (UNFPA) ha analizado las potenciales repercusiones de la pandemia de COVID-19 en la planificación familiar, así como su impacto en los otros objetivos de desarrollo sostenibles, como la eliminación de la violencia de género y el matrimonio infantil. ${ }^{2}$ Las proyecciones internacionales estiman entre 13 y 52 millones de mujeres con necesidad insatisfecha de anticoncepción, lo que implicaría entre 325,000 y 15 millones de mujeres embarazadas sin planearlo o desearlo, dependiendo de la duración y de la severidad de la afectación de los servicios de Salud Sexual y Reproductiva (SSyR) en diversos países del mundo de ingreso medio y bajo.

En la región latinoamericana, en Chile, una encuesta realizada a finales de abril de 2020 por una organización de la sociedad civil, confirma los problemas de acceso a los servicios de SSyR en estas circunstancias: ${ }^{3}$

— $72 \%$ de las usuarias no tuvo acceso a anticonceptivos en centros de salud públicos.

- 36\% no encontró la variedad de métodos solicitados.

- 34\% encontró el servicio cerrado.

- $30 \%$ vio incrementado el precio de los anticonceptivos.

Adicionalmente, se identificaron problemas de acceso para la atención de infecciones de transmisión sexual, así como para detección de cáncer cérvico-uterino y para la atención de la salud materna.

2 Fondo de Población de Naciones Unidas. "Repercusión de la pandemia de COVID-19 en la planificación familiar y la eliminación de la violencia de género, la mutilación genital femenina y el matrimonio infantil. Nota técnica provisional". Información al 27 de abril de 2020, disponible en: https://lac.unfpa.org/sites/default/files/pub-pdf/COVID-19\%20impact\%20 brief\%20for\%20UNFPA_24\%20April\%202020_ES.pdf.

3 Resultados de la Primera Encuesta sobre Acceso a la Salud Sexual y Reproductiva en tiempos de COVID-19, disponible en: https://wrere.instagram.com/p/CAacNAxpjIX/. 
Este libro forma parte del acervo de la Biblioteca Jurídica Virtual del Instituto de Investigaciones Jurídicas de la UNAM

\section{ESTIMACIONES DEL IMPACTO DE LA PANDEMIA EN LOS EMBARAZOS NO DESEADOS}

\begin{tabular}{|c|c|c|}
\hline & $\begin{array}{l}\text { Número estimado de } \\
\text { mujeres que no pueden } \\
\text { utilizar anticonceptivos } \\
\text { modernoas }\end{array}$ & $\begin{array}{l}\text { Número estimado } \\
\text { de embarazos } \\
\text { no planeados }\end{array}$ \\
\hline \multicolumn{3}{|c|}{ Interrupciones leves del servicio de salud } \\
\hline 3 meses de confinamiento & 13 millones & 325,000 \\
\hline 6 meses de confinamiento & 15 millones & 2 millones \\
\hline 9 meses de confinamiento & 18 millones & 4 millones \\
\hline 12 meses de confinamiento & 20 millones & 6 millones \\
\hline \multicolumn{3}{|c|}{ Interrupciones moderadas del servicio de salud } \\
\hline 3 meses de confinamiento & 23 millones & 600,000 \\
\hline 6 meses de confinamiento & 26 millones & 4 millones \\
\hline 9 meses de confinamiento & 28 millones & 6 millones \\
\hline 12 meses de confinamiento & 30 millones & 9 millones \\
\hline \multicolumn{3}{|c|}{ Interrupciones graves del servicio de salud } \\
\hline 3 meses de confinamiento & 44 millones & 1 millón \\
\hline 6 meses de confinamiento & 47 millones & 7 millones \\
\hline 9 meses de confinamiento & 49 millones & 11 millones \\
\hline 12 meses de confinamiento & 51 millones & 15 millones \\
\hline
\end{tabular}

FUENTE: UNFPA, abril de $2020{ }^{4}$

En México, no tenemos a la fecha información sistematizada del impacto de la pandemia en la prestación de servicios de SSyR, pero contamos con ejercicios de proyecciones, realizadas con la misma metodología internacional utilizada por UNFPA. Ejercicios preliminares del Consejo Nacional de Población (Conapo) estiman un aumento importante en la necesidad insatisfecha en anticoncepción que corresponde a algo más de un millón 172 mil mujeres en edad reproductiva que no tendrían acceso a anticoncepción a pesar de no desear embarazarse; proyectando como consecuencias 145 mil 719 embarazos no intencionados adicionales, en comparación a los esperados sin la pandemia. En relación con la fecundidad adolescente, un aumento estimado del $20 \%$ en la necesidad insatisfe-

\footnotetext{
4 Idem.
} 
Este libro forma parte del acervo de la Biblioteca Jurídica Virtual del Instituto de Investigaciones Jurídicas de la UNAM

cha redundaría en 21,575 embarazos adicionales respeto a los proyectados antes de la pandemia. ${ }^{5}$

\section{B. Impactos de la pandemia en la prestación de servicios de SSyR. Impactos directos}

Los mecanismos a través de los cuales esta pandemia está afectando la prestación y el acceso a los servicios de salud en general, y de salud sexual y reproductiva en particular, son múltiples, y afectan proporcionalmente más las regiones y los países con sistemas de salud más débiles, con brechas de desigualdades más profundas y con poblaciones más vulnerables.

Existen diversos impactos directos, que afectan la oferta de servicios, tales como:

1. La disponibilidad de los mismos, por la reconversión de hospitales, el cierre parcial o la reducción en los horarios de servicios de salud en primer nivel de atención;

2. La disponibilidad de los profesionales de salud, algunos de ellos redireccionados a servicios de atención a COVID-19, otros por presentar factores individuales de riesgo, por haberse enfermado o, en algunos casos, por haber muerto víctimas del contagio;

3. La disponibilidad de los métodos anticonceptivos, por la afectación en la cadena de suministro y abasto de insumos esenciales. En México por lo general, las adquisiciones de medicamentos en el sistema de salud se hacen de forma anual, por lo que el abasto debería estar teóricamente asegurado hasta finales de 2020. Sin embargo, es posible que el impacto se presente en el próximo ciclo de compras, afectando la gama de métodos disponibles en el sector y por ende en las opciones al alcance de la mujer. Así mismo, pueden ser afectados los costos para el sistema de salud y los costos de "bolsillo" para las mujeres. En especial, puede afectarse la oferta de los anticonceptivos de más alta efectividad y larga duración - como son los dispositivos intrauterinos y los implantes subdérmicos - y los mismos métodos quirúrgicos, como la oclusión tubárica y la vasectomía, ya que éstos necesitan obligatoriamente de la disponibilidad de profesionales de la salud capacitados y de la interacción presencial entre ellos y la persona usuaria.

5 Datos presentados en la Conferencia de prensa de la Secretaria de Salud sobre COVID-19, 4 de agosto de 2020, disponible en: https://wrwremilenio.com/politica/comunidad/ conapo-estima-145-mil-embarazos-pandemia-covid-19. 
Este libro forma parte del acervo de la Biblioteca Jurídica Virtual del Instituto de Investigaciones Jurídicas de la UNAM

4. Finalmente, ciertas barreras y restricciones normativas y la excesiva medicalización de los servicios de SSyR pueden limitar el acceso a los métodos, condicionándolo a exploraciones físicas y a estudios clínicos innecesarios, a receta médica obligatoria o a la supervisión por adultos, en caso de usuarias menores de edad.

La pandemia implica también impactos directos en la demanda de servicios, como:

1. Las restricciones en la movilidad y el transporte de las mujeres/personas usuarias

2. La menor disponibilidad de tiempo para las mujeres, que experimentan cargas adicionales del trabajo del cuidado de niñ@s y ancian@s en el hogar:

3. El temor al contagio, que aleja a mujeres, adolescentes y niñas, de los servicios de salud, aun en caso de necesidad.

4. El posible abandono, olvido, falla o uso incorrecto de los MAC, por múltiples razones, sin poder acceder a seguimiento y a alternativas adecuadas

5. Finalmente, esta situación sanitaria, económica y social puede conducir a condiciones de depresión, angustia y reducción de las motivaciones individuales para protegerse de un embarazo no deseado, con un menor autocuidado y priorización de la propria salud sexual y reproductiva.

\section{Impactos indirectos: los determinantes sociales de la salud}

Sin embargo, la pandemia no afecta solo la prestación de servicio de SSyR, ni las conductas individuales de las mujeres. Los determinantes sociales de la salud, definidos como "las circunstancias en que las personas nacen, crecen, trabajan, viven y envejecen, incluido el conjunto más amplio de fuerzas y sistemas que influyen sobre las condiciones de la vida cotidiana", son responsables de las mayores inequidades en salud en condiciones normales y asumen un rol aún más importante en tiempos de emergencias y limitación de los recursos. ${ }^{6}$ La pandemia exacerba adicionalmente la vulnerabilidad de la población indígena, rural, de las personas refugiadas y

6 Marmot M., "Social determinants of health inequalities", Lancet 2005; 365: 1099104, disponible en: https://wwrewho.int/social_determinants/strategy/Marmot-Social\%20determi nants $\% 200 \%$ 20health\%20inqualities.pdf. 
Este libro forma parte del acervo de la Biblioteca Jurídica Virtual del Instituto de Investigaciones Jurídicas de la UNAM

migrantes; de aquellas con baja accesibilidad y disponibilidad de servicios de salud, de servicios de educación formal y que viven en situación de deprivación socio-económica.

En particular, señalamos dos factores que están estrechamente vinculados con la fecundidad adolescente: la escolaridad y la pobreza.

Se sabe que la educación escolar formal, en particular más allá de la secundaria, se asocia con 2.5 años de retraso en la edad del primer hijo. Viceversa, no tener hijos/as permite a las niñas y adolescentes una mayor permanencia escolar. ${ }^{7}$

\section{ESCOLARIDAD Y FECUNDIDAD ADOLESCENTE}

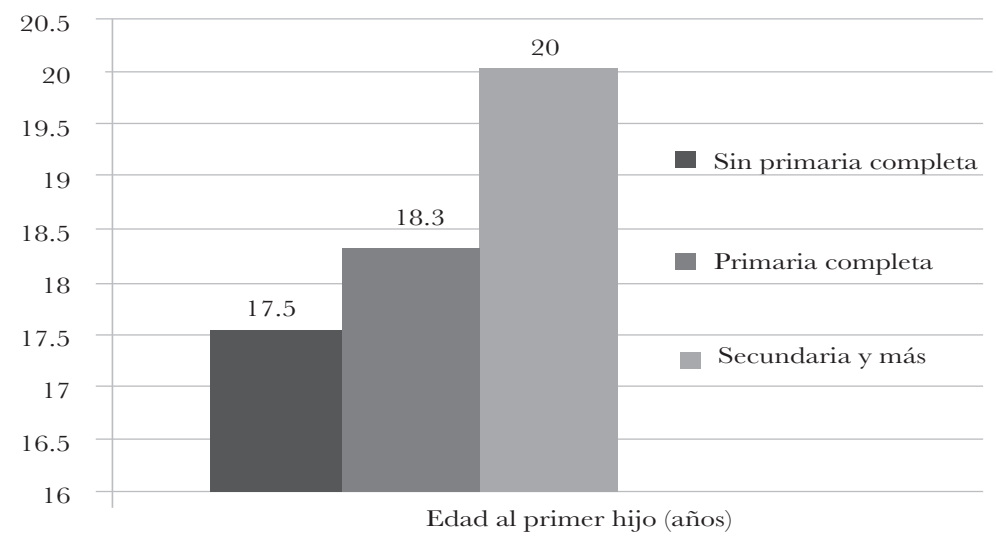

FUENTE: elaboración propia, a partir de la ENADID 2014.

Seguir en la escuela retrasa adicionalmente todas las demás transiciones sexuales y reproductivas en las niñas y las adolescentes: aplaza dos años la edad de inicio de vida sexual activa, aumenta 10 veces el uso de anticonceptivos en esa iniciación, y retrasa en tres años la edad a la primera unión. ${ }^{8}$ Son varios los mecanismos a través de los cuales la educación formal protege a las niñas y adolescentes: desde la educación sexual que se imparte en la escuela ${ }^{9}$

7 Conapo 2019, "La situación demográfica de México", disponible en: https://wrerr.gob. $m x /$ conapo/documentos/la-situacion-demografica-de-mexico-2018.

8 Urbina-Fuentes, M. et al., "La transición de los Objetivos de Desarrollo del Milenio a los Objetivos de Desarrollo Sostenible desde la perspectiva de los determinantes sociales de la salud y la equidad en salud", Gac. Med. Mex. 2017:153; 697-730, disponible en: DOI:10.24875/ GMM.M17000017, http://wrere.medigraphic.com/pdfs/gaceta/gm-2017/gm176j.pdf.

9 Hersh, A., Saavedra-Avendaño, B., Schiavon, R., Darney, B.G., "Sexuality Education During Adolescence and Use of Modern Contraception at First Sexual Intercourse Among 
Este libro forma parte del acervo de la Biblioteca Jurídica Virtual del Instituto de Investigaciones Jurídicas de la UNAM

- aun cuando sea insuficiente y no necesariamente integral - hasta las redes de protección social constituidas por su grupo de pares y por sus maestras y educadores.

Si la permanencia escolar es un factor protector, la deserción escolar priva a niñas y adolescentes de su derecho a opciones futuras y planes de vidas alternativos a los roles reproductivos tradicionales. México sigue teniendo un reto muy grande para prevenir tal deserción, a pesar de los compromisos internacionales asumidos. Solo en el ciclo escolar 2018-2019, antes de la pandemia, la tasa de abandono promedio, a nivel nacional, fue de $0.6 \%$ en educación primaria, $4.4 \%$ en secundaria y de casi $13 \%$ en educación media superior. ${ }^{10}$

La actual pandemia ha causado además una grave disrupción del ciclo escolar presencial, imponiendo nuevos aprendizajes virtuales y exigencias de conectividad que profundizan las desigualdades entre grupos sociales y probablemente aumentarán aún más el riesgo de deserción escolar de niñas y adolescentes, sobre todo aquellas en situaciones de mayor vulnerabilidad. ¿Cómo se reflejará esto, a corto y mediano plazo, en los embarazos y las uniones tempranas en estos grupos de edad?

\section{MARGINAGIÓN SOCIOEGONÓMICA Y FEGUNDIDAD ADOLESGENTE}

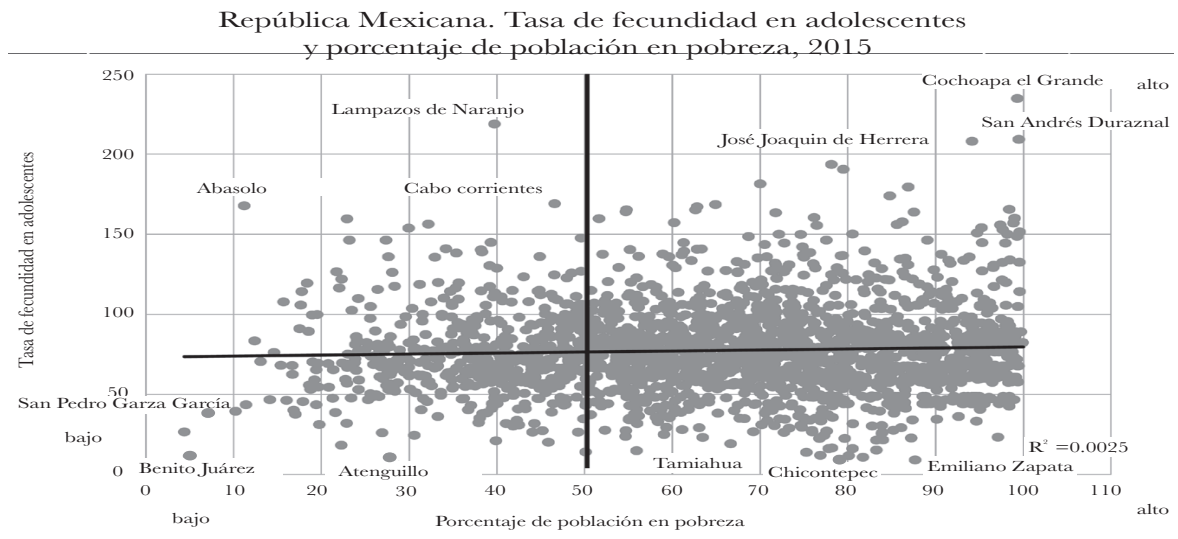

FUENTE: Conapo 2019.

Mexican Women", Fournal of Adolescent Health 65 (2019) 667e673, disponible en: https://doi. org/10.1016/j.jadohealth.2019.05.028.

10 Bernardo Moncada Rodríguez/Notimex. Deserta 13\% de estudiantes de educación media superior: SEP, 22 de junio de 2020, disponible en: https://wrere.adn40.mx/mexico/nota/ notas/2020-06-22-21-23/deserta-13-de-estudiantes-de-educacion-media-superior-sep. 
Este libro forma parte del acervo de la Biblioteca Jurídica Virtual del Instituto de Investigaciones Jurídicas de la UNAM

Por otro lado, sabemos que existe una relación directa entre marginación socioeconómica y la fecundidad general, pero en particular, la fecundidad adolescente. Análisis recientes del Conapo confirman esta relación a nivel municipal: a mayor grado de marginación socio-económica, mayor fecundidad adolescente. ${ }^{11}$

La pandemia está también agudizando de una manera sin precedentes la crisis económica y profundizando las inequidades entre y adentro de los países. ¿Cómo impactará el empeoramiento de la economía, particularmente de las economías informales, y el aumento de la pobreza en la fecundidad temprana?

Es muy probable que estos determinantes sociales, modulados negativamente por la pandemia, tengan un efecto brutal en la salud sexual y reproductiva de la población, sumándose, en el mediano y largo plazo, a los impactos directos ya analizados. Es un imperativo ético, por parte de los Estados y de los gobiernos, diseñar e implementar intervenciones focalizadas para cada uno de estos ámbitos (la salud, la educación, la reducción de la pobreza) pero vinculadas de manera intersectorial, suportadas por asignaciones presupuestales suficientes y rigurosamente aplicadas, para mitigar lo más posible los impactos tan adversos e inequitativos que anticipamos en la salud y los derechos de nuestra población, en particular de nuestras mujeres, adolescentes y niñas.

Un muy reciente informe conjunto de la Comisión Económica para América Latina y el Caribe (CEPAL) y la Organización Panamericana de la Salud analiza la vulnerabilidad de la región, debida a los altos niveles de informalidad laboral, la elevada concentración urbana y al mismo tiempo la profunda dispersión rural, la pobreza y la desigualdad, así como la fragilidad de sus sistemas de salud y de protección social, y señala como la pandemia profundiza esta vulnerabilidad, y como deba ser enfrentada, con inversiones dirigidas y claros compromisos en políticas públicas. ${ }^{12}$

\section{La vulnerabilidad de las mujeres como trabajadoras del cuidado en las instituciones de salud}

Un altísimo porcentaje del personal de salud está constituido por mujeres, proporcionalmente muchas más en la base de la pirámide: trabajadoras

11 Conapo 2019, "La situación demográfica de México", op. cit.

12 Comisión Económica para América Latina y el Caribe-Organización Panamericana de la Salud. Salud y economía: una convergencia necesaria para enfrentar el COVID-19 y retomar la senda hacia el desarrollo sostenible en América Latina y el Caribe. Informe COVID-19, CEPAL-OPS, 30 de julio de 2020, disponible en: https://repositorio.cepal.org/bit stream/handle/11362/45840/4/S2000462_es.pdf. 
Este libro forma parte del acervo de la Biblioteca Jurídica Virtual del Instituto de Investigaciones Jurídicas de la UNAM

sociales, laboratoristas, enfermeras, y médicas generales. Sin embargo, conforme sube la pirámide - médicos especialistas, jefes de servicios, directores de hospitales y autoridades y funcionarios en salud - se invierte la tendencia y se masculiniza la profesión, haciendo además muy patente el fenómeno del techo de cristal para las mujeres profesionistas.

En Estados Unidos, se estima que el 78\% del personal de salud son mujeres; ellas constituyen casi 9 de cada 10 enfermeras y auxiliares de enfermería, la gran mayoría de terapeutas respiratorios, la mayoría de los farmacéuticos y una abrumadora mayoría de auxiliares y técnicos de farmacia. ${ }^{13}$

De manera similar, en Latinoamérica, las mujeres se ven particularmente afectadas por la presión sobre los sistemas de salud porque representan el 72.8\% de las personas empleadas en el sector en la región. Esta situación se ha dado en un contexto regional de persistente discriminación salarial: los ingresos de las mujeres que trabajan en el sector de la salud son un 25\% inferiores a los de los hombres del mismo sector. ${ }^{14}$ Ya desde 2018, la Organización Mundial de la Salud señalaba que el 70\% del personal sociosanitario mundial es femenino; sin embargo, la mitad de la contribución de las mujeres a la salud mundial, que equivale a 3 billones de dólares anuales, no se remunera. ${ }^{15}$

En relación con la actual pandemia, esto ha implicado que más mujeres han estado en la trinchera, en contacto directo con las personas infectadas y enfermas: se estima que en Wuhan, China, al menos el $72 \%$ del personal de salud eran mujeres, con picos localizados de hasta el $90 \% .{ }^{16} \mathrm{En}$ los asilos de ancianos de todo el mundo, donde ha arrasado el contagio, el personal del cuidado es mayoritariamente femenino, lo que las pone directamente en la boca del virus, con un desgaste muy elevado de su salud física y mental. La mayor presión sobre los sistemas de salud origina condiciones extremas de trabajo, como los largos turnos, aumentando el riesgo de que los trabajadores sanitarios se infecten con el virus y que lo transmitan a sus

13 Robertson, C. y Gebeloff, R., "How Millions of Women Became the Most Essential Workers in America", The New Tork Times, 18 de abril de 2020, disponible en: https://wwre. nytimes.com/2020/04/18/us/coronavirus-women-essential-workers.html.

14 Comisión Económica para América Latina y el Caribe. The COVID-19 pandemic is exacerbating the care crisis in Latin America and the Caribbean. CEPAL, abril de 2020, disponible en: https://repositorio.cepal.org/bitstream/handle/11362/45352/1/S2000260_en.pdf.

15 Fact sheets, World Health Organization 2020 https://wrere.who.int/es/news-room/factsheets/detail/women-s-health.

16 Li G. et al., "Psychological impact on women health workers involved in COVID-19 outbreak in Wuhan: a cross-sectional study", F Neurol Neurosurg Psychiatry 2020; 91:895-897, disponible en: DOI:10.1136/jnnp-2020-323134, https://jnnp.bmj.com/content/jnnp/91/8/895. full.pdf. 
Este libro forma parte del acervo de la Biblioteca Jurídica Virtual del Instituto de Investigaciones Jurídicas de la UNAM

familiares. Las mujeres que trabajan en el sector de la salud siguen además siendo responsables del cuidado doméstico y de las personas dependientes dentro de sus hogares.

Las mujeres constituyen en suma la columna esencial del trabajo del cuidado en salud, en educación, en protección social, en la cura de la primera infancia, de la tercera y cuarta edad y de las personas con discapacidad, reproduciendo una vez más los roles tradicionales que la norma social les ha asignado. La mayoría de estos puestos de trabajos son informales; y aun cuando se vuelven profesionalizados y remunerados, las mujeres que los ejecutan son con frecuencia pagadas de manera insuficiente y con importantes brechas de género salariales y regulatorias. Finalmente, este panorama demuestra como aún el trabajo "formal" del cuidado de la salud y de la protección social se naturaliza automáticamente como un trabajo de mujeres.

No podemos cerrar esta sección sin una referencia obligada: "In Memoriam: Healthcare Workers Who Have Died of COVID-19", un conmovedor listado de decenas de centenares de hombres y mujeres, personal médico, de enfermería y otro personal de salud en todo el mundo que, profundamente comprometidos con un trabajo difícil y agotador, dejaron su vida en el frente del deber profesional y de una inquebrantable responsabilidad ética. ${ }^{17}$

\section{La vulnerabilidad de las mujeres como trabajadoras del cuidado en el hogar}

Durante los periodos de encierre domiciliario (que se anuncian desgraciadamente largos en la mayoría de los países), las mujeres se encuentran aún más que de costumbre, aisladas en sus casas. Esta situación tiene un doble impacto: sobre la carga del trabajo del cuidado, por un lado, y sobre las múltiples formas de violencia de género que se originan en el hogar por el otro.

\section{A. Impacto de la pandemia en la carga del trabajo doméstico}

La carga del "cuidado" doméstico desde siempre recae sobre la espalda de las mujeres, ya sean mujeres que cuidan de sus familias o mujeres trabajadoras del hogar que cuidan de las familias de otras/os. Un informe reciente de la CEPAL, publicado poco antes de que explotara la pandemia,

17 "In Memoriam: Healthcare Workers Who Have Died of COVID-19", disponible en: https://wwre.univadis.es/viewarticle/in-memoriam-healthcare-workers-who-have-died-of-covid-19-719345. El listado solo está actualizado al 29 de abril 2020. 
Este libro forma parte del acervo de la Biblioteca Jurídica Virtual del Instituto de Investigaciones Jurídicas de la UNAM www.juridicas.unam.mx

da cuenta de las inequidades de género en la economía del cuidado en toda la región. ${ }^{18}$

\section{AMÉRICA LATINA: PROPORCIÓN DE TIEMPO DEDICADO \\ A QUEHACERES DOMÉSTICOS Y GUIDADOS \\ NO REMUNERADOS, SEGÚN SEXO}

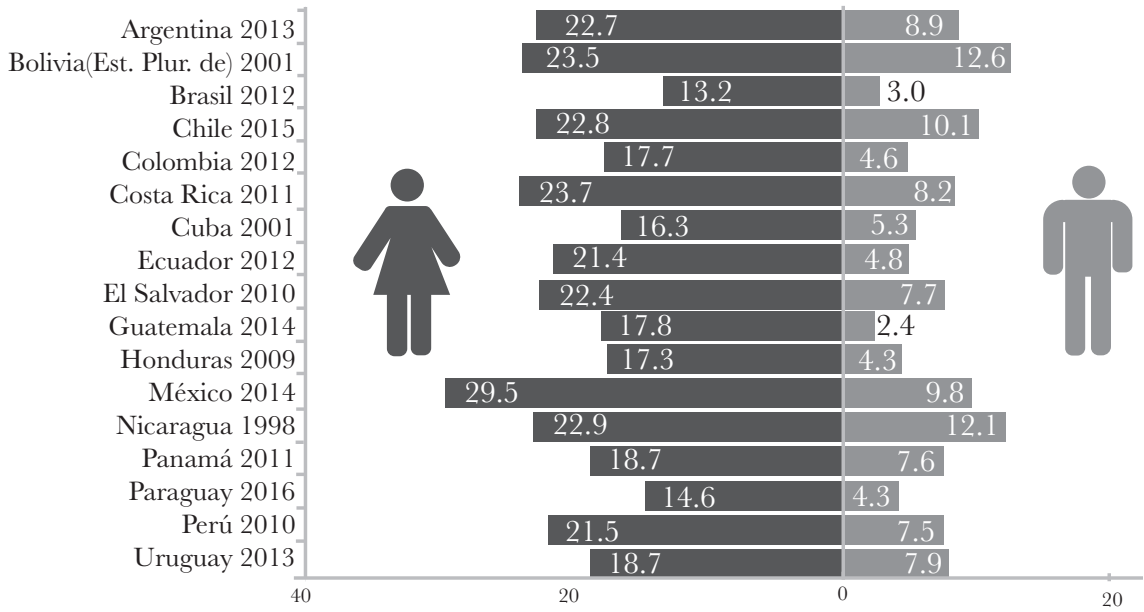

Fuente: Comisión Económica para América Latina y el Caribe (CEPAL 2019).

De acuerdo con las encuestas del uso de tiempo, la repartición desigual por sexo de los diversos trabajos del cuidado y trabajos domésticos es común a todos los países de la región, por factores que van de dos a ocho veces más: en México, en términos porcentuales, las mujeres les dedican tres veces más tiempo que los hombres. ${ }^{19}$ Este fenómeno se presenta además en todos los niveles socioeconómicos: siempre en México, el porcentaje del uso de tiempo de las mujeres disminuye ligeramente conforme incrementa el

18 Comisión Económica para América Latina y el Caribe. La autonomía de las mujeres en escenarios económicos cambiantes. CEPAL, enero de 2020, disponible en: https://reposi torio.cepal.org/bitstream/handle/11362/45032/S1900723_es.pdf? sequence $=4$.

19 Comisión Económica para América Latina y el Caribe. Repositorio de información sobre uso del tiempo de América Latina y el Caribe "Sistemas de información: transformar datos en información, información en conocimiento y conocimiento en decisión política" Eje 9 de la Estrategia de Montevideo para la Implementación de la Agenda Regional de Género en el marco del Desarrollo Sostenible hacia 2030. CEPAL 2020, disponible en: https:// wrwre.cepal.org/sites/default/files/news/files/folleto_repositorio_de_informacion_sobre_uso_del_tiem po_de_america_latina_y_el_caribe.pdf. 
Este libro forma parte del acervo de la Biblioteca Jurídica Virtual del Instituto de Investigaciones Jurídicas de la UNAM

percentil de ingresos, pero no aumenta proporcionalmente el porcentaje que le dedican los hombres. Esto sugiere que, a mayor nivel socio-económico, la carga se delega parcialmente a las trabajadoras domésticas, sin cambio en la distribución social de los roles.

Tiempo dedicado al trabajo del cuidado doméstico por sexo y por nivel socio-económico

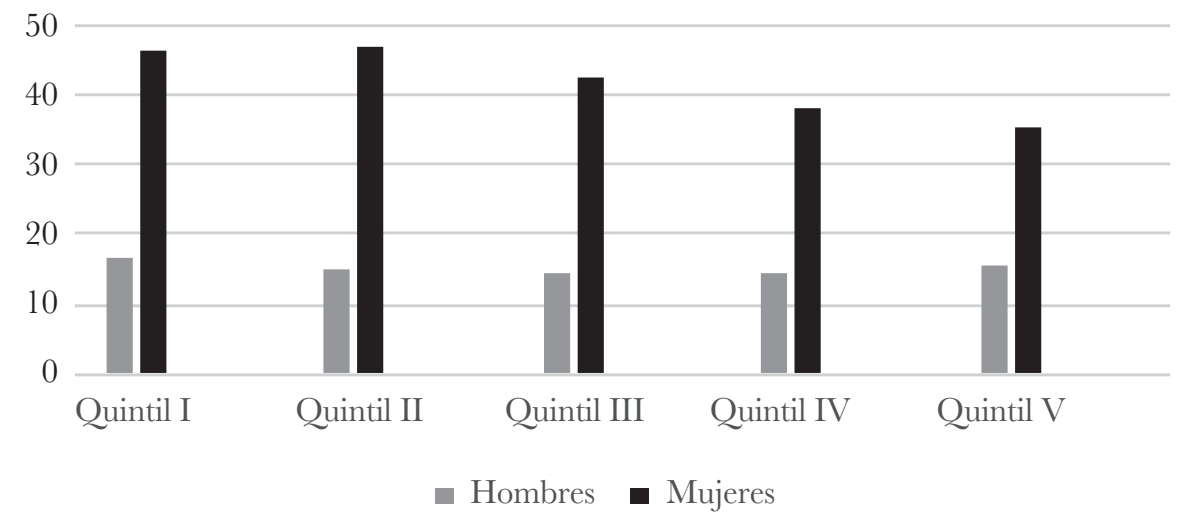

FUENTE: elaboración propia,con base en CEPAL 2020. ${ }^{20}$

Pero la pandemia y el encierro implican que las mujeres enfrenten una carga todavía más pesada, agravada por la presencia de los hijos en la casa, debido al cierre de las escuelas, por los maridos y parejas en home-work, por los parientes más ancianos a cargo, para sustraerlos del peligro del contagio en residencias y asilos. Por supuesto, también las mujeres profesionistas se ven obligadas al trabajo en línea desde casa; pero ellas, adicionalmente, siguen con las demás tareas domésticas, que además se acentúan exponencialmente por las carencias económicas.

\section{B. Impacto de la pandemia en la violencia doméstica}

Finalmente, el encierro doméstico impacta en la violencia de género contra las mujeres, definida como "toda acción u omisión que, basada en su género y derivada del uso o abuso del poder, tenga por objeto o resultado un daño o sufrimiento físico, psicológico, patrimonial, económico, sexual o 
Este libro forma parte del acervo de la Biblioteca Jurídica Virtual del Instituto de Investigaciones Jurídicas de la UNAM

la muerte a las personas mujeres, tanto en el ámbito público como privado, que limite su acceso a una vida libre de violencia". ${ }^{21}$

El UNFPA prevé que la pandemia resulte en 15 millones de casos adicionales de violencia de género por cada 3 meses de confinamiento, causados por un aumento directo de la misma, aunados a una reducción de las intervenciones de prevención y protección, y de servicios sociales. ${ }^{22}$

Como afirma la relatora especial de las Naciones Unidas sobre la violencia contra la mujer: "Para demasiadas mujeres y niños, el hogar puede ser un lugar de miedo y abuso. Esa situación empeora ...en casos de aislamiento... durante la pandemia del COVID-19", con el riesgo de que aumente la violencia doméstica, emocional, física y sexual, incluidos los feminicidios. "El riesgo se agrava en un momento en que no hay o hay menos refugios y servicios de ayuda disponibles para las víctimas; cuando es difícil acceder a aquellos que aún están abiertos; y cuando hay menos apoyo de la comunidad; menos intervenciones policiales y menos acceso a la justicia ya que muchos tribunales están cerrados". ${ }^{23}$ De la misma manera, el Instituto Nacional de las Mujeres señala que la pandemia del COVID-19 impacta de manera diferenciada a las mujeres y las niñas, aumentando su exposición a la violencia de género entre las paredes domésticas; invita por tanto a todas las instituciones dedicadas a prevenir, atender y sancionar la violencia hacia las mujeres, a que refuercen intervenciones de información y de actuación en el marco de sus competencias. ${ }^{24}$

Sin embargo, los datos que se van recabando en estos meses ya están dando cuenta del pesante impacto del encierro en la violencia de género. Las muertes violentas de mujeres han aumentado entre enero-abril 2019, contra el mismo periodo de 2020: si bien el feminicidio disminuyó en 2.1\%, los homicidios dolosos se incrementaron en 11.7\%. La Comisión Ejecutiva

21 Gaceta Oficial de la Ciudad de México, 19 de Mayo de 2017. "Lineamientos para promover el uso de un lenguaje incluyente y una imagen de las mujeres libre de prejuicios y estereotipos en las campañas publicitarias y en toda aquella información que difundan las Dependencias, Entidades y Órganos Político-Administrativos de la Ciudad de México", disponible en: https://docplayeres/50126805-10-gaceta-oficial-de-la-ciudad-de-mexico-19-de-mayo-de-consideran do.html.

22 Fondo de Población de Naciones Unidas. "Repercusión de la pandemia de COVID-19 en la planificación familiar...”, op. cit.

23 Noticias ONU. El coronavirus golpea tres veces a las mujeres: por la salud, por la violencia doméstica y por cuidar de los otros. 27 marzo 2020, disponible en: https://news.un.org/ es/story/2020/03/1471872.

24 Instituto Nacional de las Mujeres. Ante coronavirus, Inmujeres llama a prevenir violencia hacia mujeres y corresponsabilidad cuidados. Comunicado, 18 de marzo de 2020, disponible en: https://wrwe.gob.mx/inmujeres/prensa/ante-coronavirus-inmujeres-llama-a-prevenirviolencia-hacia-mujeres-y-corresponsabilidad-cuidados. 
Este libro forma parte del acervo de la Biblioteca Jurídica Virtual del Instituto de Investigaciones Jurídicas de la UNAM

de Atención a Víctimas informa que, entre 2019 y 2020, han aumentaron las solicitudes a los Centros de Justicia de las Mujeres de atención psicológica, médica y de servicio social. Han aumentado las llamadas de auxilio por razones de violencia familiar y de género a la línea de atención telefónica 911: de las más de 22 millones y 800,000 llamadas recibidas, un 7.4\% fueron relacionadas con eventos de violencia de género. ${ }^{25}$ La situación desdibujada por estos informes es aún más preocupante si consideramos que seguramente subestiman la realidad: en situaciones de encierro, las mujeres, las adolescentes y las niñas enfrentan mayores dificultades para solicitar auxilio, para denunciar, así como para buscar y recibir atención en salud, psicológica, legal y judicial.

Finalmente, desconocemos todavía cómo esto se reflejará, en el corto y mediano plazo, en un aumento de los embarazos no intencionados, o en aquellos que son resultado de la violencia; cuántas mujeres, niñas y adolescentes puedan, en estas condiciones, tener acceso a servicios inmediatos de prevención y atención, desde anticoncepción de emergencia hasta el aborto seguro, en el marco legal existente. Recordamos que la Interrupción Voluntaria del Embarazo (IVE) es legal en todo el país en caso de violencia sexual, aun cuando la Interrupción Legal del Embarazo (ILE) es legal bajo solicitud de la mujer sólo en la Ciudad de México y Oaxaca. Pero es una obligación del Estado y del sector salud anticipar un potencial aumento de la demanda de estos servicios, para que las mujeres en tales circunstancias sean atendidas con capacidad operativa, de atención o de referencia inmediata, sin discriminación de edad, de estatus social u otras condiciones de vulnerabilidad.

\section{CONCLUSIONES. CÓMO PROTEGER LOS DERECHOS}

\section{Y LA SALUD SEXUAL Y REPRODUCTIVA EN TIEMPOS DE PANDEMIA}

Ante estas situaciones aumenta significativamente el riesgo de vulneración al derecho de toda mujer, niña y adolescentes a la vida, a la salud, a la información, a la educación, a la autonomía reproductiva, a los planes de vida, a gozar del beneficio del más alto nivel del progreso científico, a una vida libre de violencia y a la igualdad. ¿Como seguir garantizando y protegiendo estos

25 Centro de Investigación y Docencia Económica. Violencia de Género en tiempos de COVID-19. CIDE, 11 de mayo de 2020, disponible en: https://wrere.cide.edu/coronavirus /2020/05/11/violencia-de-genero-en-tiempos-de-covid-19/.

Instituto Nacional de las Mujeres, Violencia contra las mujeres. Indicadores en tiempos de pandemia. InMujeres, 19 de junio de 2020, disponible en: https://wrwr.gob.mx/inmujeres/ documentos/violencia-contra-las-mujeres-indicadores-en-tiempos-de-pandemia. 
Este libro forma parte del acervo de la Biblioteca Jurídica Virtual del Instituto de Investigaciones Jurídicas de la UNAM

derechos y la salud de mujeres, niñas y adolescentes, aun en tiempos de restricciones de movilidad, de crisis económica, de emergencias sanitarias y de uso de recursos limitados en salud?

\section{Los servicios de salud sexual y reproductiva son servicios esenciales y no diferibles en el tiempo}

En las circunstancias actuales de la pandemia, se vuelve un imperativo ético de los sistemas de salud priorizar los recursos escasos para seleccionar y mantener los servicios esenciales que necesita la población de manera colectiva y las personas de manera individual, limitando la mortalidad directa inducida por la pandemia y la mortalidad indirecta debida a todas las demás causas. Los servicios de salud sexual, reproductiva, materna y neonatal se consideran esenciales y no diferibles en el tiempo, y deberán ser otorgados de manera prioritaria aun en época de pandemia, ya que su negación o dilación temporal causaría un daño grave, prevenible e injustificado a las mujeres, niñas y adolescentes. La atención de la salud en general, y de la salud sexual y reproductiva en particular, es un derecho, establecido en normas internacionales y nacionales, y que debe poder ser gozado por todas las mujeres, sin discriminación, garantizando una cobertura y acceso universal de los servicios de salud, accesibles, disponibles y de calidad, sin dejar a nadie atrás. ${ }^{26}$ México ha estado a la vanguardia en promover estos derechos y en ratificar su compromiso para garantizar la cobertura universal en salud, en diferentes foros internacionales, así como a través del marco constitucional, legal y programático del país. ${ }^{27}$

De acuerdo con las recomendaciones internacionales, el Centro Nacional de Equidad de Género y Salud Reproductiva (CNEGSR) en México también ratifica que "Todas las mujeres embarazadas... deben tener acceso a servicios de calidad, incluyendo atención obstétrica, neonatal, aborto seguro (en los marcos previstos por la ley), anticoncepción postevento obstétrico, prevención y atención de la violencia y apoyo psicosocial o en salud mental, según se requiera". ${ }^{28}$

26 UNSSC Knowledge Centre for Sustainable Development, La Agenda 2030 para el Desarrollo Sostenible, disponible en: https://wrewe.unssc.org/sites/unssc.org/files/2030_agenda_for_sustainable_development_-_kcsd_primer-spanish.pdf.

27 Secretaria de Salud, Programa Sectorial de Salud 2020-2024, 17 de agosto de 2020. disponible en: https://wrere.gob.mx/salud/documentos/programa-sectorial-de-salud-2020-2024.

28 Centro Nacional de Equidad de Género y Salud Reproductiva. Lineamiento para la prevención y mitigación de GOVID-19 en la atención del embarazo, parto, puerperio y de la persona recién nacida. GNEGSR, Versión 1, 10 de abril de 2020, disponible en: https://wrere. 
Este libro forma parte del acervo de la Biblioteca Jurídica Virtual del Instituto de Investigaciones Jurídicas de la UNAM

Sin embargo, las acciones declarativas no son suficientes. Se necesitarán compromiso político y presupuesto. La CEPAL señala que las acciones en salud para el control de la pandemia, así como las acciones destinadas a la reactivación de las economías regionales, requieren liderazgo y rectoría de los Estados, a través de políticas públicas en salud, protección social y políticas económicas. Esto será posible solo vía el aumento del gasto fiscal, incluyendo un gasto en salud de al menos el $6 \%$ del producto interno bruto. ${ }^{29}$

\section{Flexibilidad e inovación en salud}

Cada uno de los innegables retos - descritos a la largo de este capítulo - que presenta esta pandemia para la SSyR y para la igualdad de género de las mujeres, ofrece también ventanas de oportunidades específicas para generar nuevos modelos de atención y de conducta, que debemos aprovechar de manera innovadora, creativa y solidaria, no solo durante la contingencia, sino más allá de ella.

En la atención en salud en general, existe la oportunidad de generar nuevos modelos de atención a distancia, en línea, de video-consultas y telemedicina adaptada a las emergencias del COVID-19. ${ }^{30}$ Tales soluciones innovadoras y flexibles permiten asegurar el acceso a diversos servicios en salud sexual y reproductiva: desde la anticoncepción hasta el aborto con medicamentos, a través de consultas virtuales, entrega de recetas electrónicas o envío a domicilio, dotaciones de ciclos de anticonceptivos o antirretrovirales mayores a lo habitual. Todas ellas son prácticas basadas en evidencias, altamente costo-efectivas, que permiten utilizar al máximo los recursos escasos (incluyendo los recursos humanos), aumentando la adherencia y la efectividad sin afectar la seguridad de las prestaciones. ${ }^{31}$

Por otro lado, deberían aprovecharse las actuales experiencias tan intensas de las/los profesionales de la salud y de sus pacientes, para construir

gob.mx/cms/uploads/attachment/file/546239/Lineamiento_prevencion_y_mitigacion_de_COVID-19_ en_el_embarazo_CNEGSR_1_.pdf, y, Versión 2, del 20 julio de 2020, https://coronavirus.gob.mx/ wp-content/uploads/2020/07/Lineamientos_Prevencion_COVID19_Embarazos_V2.pdf.

29 Comisión Económica para América Latina y el Caribe. The COVID-19 pandemic..., op. cit.

30 Special Collection - Coronavirus (COVID-19): remote care through telehealth, 6 de mayo de 2020, disponible en: https://wrere.cochrane.org/newes/special-collection-coronavirus-covid19-remote-care-through-telehealth.

31 The Faculty of Sexual and Reproductive Healthcare (FSRH), Royal College of Obstetricians and Gynecologists, UK. COVID-19 Resources and Information for SRH Professionals, disponible en: https://www:fsrh.org/fsrh-and-covid-19-resources-and-information-for-srh/. 
Este libro forma parte del acervo de la Biblioteca Jurídica Virtual del Instituto de Investigaciones Jurídicas de la UNAM

nuevos modelos de atención, más comunitarios y colectivos, más compasivos y humanistas. De acuerdo con Rita Segato, socióloga y feminista argentina con larga trayectoria académica y significativas contribuciones al campo de los derechos humanos, la antropología, los estudios de género y la ética pública, esta pandemia ha hecho patente la vulnerabilidad de todo el personal médico a la par de sus pacientes, poniéndonos a todas y todos en (casi) el mismo nivel ante la enfermedad y la muerte, revolucionando en parte la concepción autoritaria, vertical y jerárquica que rige la medicina occidental. En esta conciencia de la vulnerabilidad común, podría radicar una nueva concepción de la relación médico-paciente, más horizontal y democrática. Deberían surgir así mismo, modelos de trabajo con redistribución más equitativa de tareas (task-sharing) entre jerarquías profesionales y diversos cuadros de profesionales de la salud, pero también entre géneros, con políticas laborales y remuneraciones más igualitarias, que valoricen e impulsen el trabajo de las mujeres en el sector de la salud y del cuidado en general. ${ }^{32}$

\section{Igualdad de género}

Finalmente, no hay soluciones para la sociedad si no hay soluciones para las mujeres. Y para eso, se necesita igualdad. La pandemia ha puesto aún más al desnudo las desigualdades, de género y de poder, que se expresan e interactúan de manera estructural en la sociedad: desde las creencias, conocimientos, actitudes y comportamientos individuales; las relaciones y las dinámicas familiares, pasando por las normas comunitarias y sociales hasta las políticas y los marcos regulatorios nacionales e internacionales. El resultado es la división estereotipada de los roles bio-psico-sociales: el rol productivo del hombre vs. el rol reproductivo y del cuidado de la mujer. La desigualdad de género a su vez nutre y cultiva las raíces de la violencia de género, asume una supuesta superioridad natural del hombre sobre la mujer (física, intelectual, económica, etc.) que pretende restarle a la mujer derechos, autonomía e independencia física, emocional, reproductiva, económica, patrimonial, civil y legal. Mientras no se revierta sistemáticamente esta perspectiva, mientras no se erradique la violencia, mientras no se camine firmemente hacia la igualdad, desde el hogar hasta el ámbito laboral, social

32 World Health Organization (WHO), Global strategy on human resources for health: workforce 2030, Geneva, WHO, 2016, disponible en: https://wrere.who.int/hrh/resources/pub_ globstrathrh-2030/en/. 
Este libro forma parte del acervo de la Biblioteca Jurídica Virtual del Instituto de Investigaciones Jurídicas de la UNAM

y político, no habrá solución verdadera. El estado debe estar más que nunca vigilante para proteger a las mujeres de la violencia, y también para garantizar su igualdad de oportunidades ante la crisis causada por la pandemia así como ante la futura recuperación.

Por otro lado, las actuales circunstancias del encierro y de largas convivencias diarias están visibilizando más que nunca la carga desproporcionada del trabajo doméstico de las mujeres. Es posible y deseable que se abra así una ranura sutil de oportunidad para aprender desde el hogar un nuevo contrato más solidario y más equitativo de convivencia y de repartición de las tareas del cuidado entre los miembros del núcleo familiar: entre las diferentes generaciones, entre los padres y los hijos, pero sobre todo, entre mujeres y hombres. Ojalá esta sea la semilla de una nueva masculinidad posible y de una nueva, necesaria igualdad. 